\title{
PENGARUH UKURAN PERUSAHAAN, UMUR PERUSAHAAN, LEVERAGE, RETURN ON ASSETS DAN KOMISARIS INDEPENDEN TERHADAP PENGUNGKAPAN INTELLECTUAL CAPITAL (PADA PERUSAHAAN MANUFAKTUR YANG TERDAFTAR DI BURSA EFEK INDONESIA PERIODE 2013-2016)
}

\author{
Mulyadi ${ }^{1}$ \\ *Prodi Akuntansi, Fakultas Ekonomi dan Bisnis, Universitas Muhammadiyah Tangerang \\ *mulyadi@umt.ac.id ${ }^{l}$ \\ Siska Ariyanti ${ }^{2}$ \\ *Prodi Akuntansi, Fakultas Ekonomi dan Bisnis, Universitas Muhammadiyah Tangerang \\ *siska.ariyanti20@gmail.com ${ }^{2}$
}

\begin{abstract}
The purpose of this research is to know the effect of firm size, age of company, leverage, return on assets and commissioner independent partially and together at Manufacturing companylisted on the Indonesia Stock Exchange (IDX). The research period used is 4 years the period 2013-2016.

The study population includes all Manufacturing companies listed on Indonesia Stock Exchange period 2013-2016. Technique of Sampling by using technique of purposive sampling. Based on the predetermined criteria a sample of 20 companies was obtained. The type of data used is secondary data obtained from the Indonesia Stock Exchange website. method of data analysis used regression analysis of panel data.

The results of this study indicate that return on assets affect the diosclosure of of intellectual capital, while firm size, age of company, leverage, and independent commissioner have no effect on intellectual capital disclosure.
\end{abstract}

Keywords: Firm Size, Age of Company, Leverage, Return On Assets, Independent Commissioner, Intellectual Capital Disclosure 


\section{PENDAHULUAN}

Penggunaan ilmu pengetahuan dan teknologi informasi secara efisien dan ekonomis dapat memicu pertumbuhan organisasi berbasis knowledge yang dapat memberikan keunggulan kompetitif perusahaan serta menjadi senjata untuk memenangkan persaingan bisnis, Yusuf dan Sawitri (2009) dalam Mahardika, dkk (2014). Para pelaku bisnis mulai menyadari bahwa kemampuan bersaing tidak hanya terletak pada kepemilikan mesin-mesin industri tetapi lebih pada inovasi, informasi, pengelolaan organisasi dan knowledge sumber daya manusia yang dimilikinya. Oleh karena itu, organisasi bisnis semakin menitik beratkan pentingnya aset pengetahuan sebagai salah satu bentuk aktiva tidak berwujud (Agnes dalam Puasanti, 2013).

Salah satu pendekatan yang digunakan dalam penilaian dan pengukuran intangible asset (aktiva tidak berwujud) adalah Intellectual Capital, Petty dan Guthrie (dalam Ulum, 2009). Di Indonesia, Intellectual Capital mulai berkembang terutama setelah munculnya Pernyataan Standar Akuntansi Keuangan (PSAK) No.19 (revisi 2000) tentang aset tidak berwujud. Menurut PSAK No.19 (revisi 2009), aset tidak berwujud adalah aset non moneter yang dapat diidentifikasi dan tidak mempunyai wujud fisik serta dimiliki untuk digunakan dalam menghasilkan atau menyerahkan barang atau jasa, disewakan kepada pihak lainnya, atau untuk tujuan administratif, Ulum (2009).

Dengan adanya PSAK No.19 membuktikan bahwa Intellectual Capital di Indonesia telah mendapatkan perhatian. Beberapa contoh dari aktiva tidak berwujud sendiri telah disebutkan dalam PSAK No.19 paragraf 09 antara lain ilmu pengetahuan dan

teknologi, desain dan implementasi sistem atau proses yang baru, lisensi, hak kekayaan intelektual, pengetahuan mengenai pasar dan merk dagang (termasuk merek produk/brand names). Selain itu juga ditambahkan bahkan piranti lunak komputer, hak paten, hak cipta, film gambar hidup, daftar pelanggan, hak pengusaha hutan, kouta impor, waralaba, hubungan dengan pemasok atau pelanggan, kesetiaan pelanggan, hak pemasaran dan pangsa pasar, Ulum, (2009).

Meskipun Intellectual Capital telah disinggung secara implisit dalam PSAK No.19 (revisi 2009), tetapi implementasi dari Intellectual Capital itu sendiri masih kurang. Hal tersebut dikarenakan sampai dengan saat ini masih banyak perusahaan-perusahaan di Indonesia yang cenderung menggunakan basis konvensional (convesional based) dalam menjalankan bisnisnya, Ramadhan (2016).

Abidin (dalam Ramadhan, 2016) menyatakan perusahaan-perusahaan di Indonesia akan dapat bersaing secara global dengan menggunakan keunggulan kompetitif yang diperoleh melalui inovasi-inovasi kreatif yang dihasilkan oleh Intellectual Capital. Hal tersebut tentunya akan dapat mendorong terciptanya produk-produk yang semakin menarik minat dari para konsumen.

Intellectual Capital menjadi faktor penentu utama perolehan laba suatu perusahan dan dianggap sebagai suatu kekuatan dalam mencapai kesuksesan dalam dunia bisnis. Oleh karena itu, penting untuk menilai Intellectual Capital dari suatu perusahaan dan juga meneliti faktor-faktor yang mempengaruhi Intellectual Capital karena dalam jangka panjang hal ini akan memberikan kontribusi pada keunggulan kompetitif perusahaan, Saleh et al., (dalam Puasanti, 2013).

Menurut Marwan dan Ghani (2011) dalam Ramadhan (2016). Intellectual Capital sebagai total dari aset tidak berwujud terkait dengan pengetahuan tentang perusahaan yang telah disusun dan dimanfaatkan untuk menghasilkan aset bernilai tinggi dan menciptakan keunggulan saing. Perusahaan yang mengungkapkan informasi mengenai Intellectual Capital akan mendapatkan manfaat yang menguntungkan bagi organisasi.

Beberapa manfaat Intellectual Capital antara lain untuk membentuk organisasi merumuskan strategi, menilai eksekusi strategi, membentuk dalam keputusan diversifikasi dan ekspansi, digunakan sebagai dasar untuk kompensasi dan mengkomunikasikan langkahlangkah bagi stakeholder eksternal (Farneti et al., dalam Ashari dan Putra, 2016). 
Ferreira (2011) dalam Ashari dan Putra (2016) menjelaskan manfaat lain dari Intellectual Capital, yaitu meningkatkan transparansi dengan lebih mengungkapkan intangible information daripada tangible information, meningkatkan kepercayaan pekerja dan stakeholder yang lain pada perusahaan dan mendukung visi jangka panjang organisasi. Di Indonesia, informasi terkait dengan Intellectual Capital yang diungkapkan oleh perusahaan-perusahaan masih minim.

Hal ini terjadi belum ada standar akuntansi yang mewajibkan perusahaan untuk mengungkapkan informasi tentang Intellectual Capital dalam laporan keuangan perusahaan. PSAK sebagai standar akuntansi keuangan yang berlaku di Indonesia tidak mengatur secara eksplisit tentang Intellectual Capital. PSAK No.19 (revisi 2009) mengatur tentang aset tidak berwujud. Namun, dalam regulasi tersebut tidak mengatur bagaimana cara pengukuran dan itemitem Intellectual Capital apa saja yang perlu diungkapkan, Fitriani (2012) dalam Prabowo (2014).

\section{KAJIAN PUSTAKA \\ PENGEMBANGAN HIPOTESIS}

DAN

\section{Teori Stakeholder (Grand Theory)}

Berdasarkan teori stakeholder, menyatakan bahwa semua stakeholder mempunyai hak untuk diberikan informasi mengenai aktifitas perusahaan. Para stakeholder tersebut bisa memilih untuk tidak menggunakan informasi tersebut dan juga mereka tidak dapat secara langsung memainkan peranan untuk membangun keberlangsungan usaha perusahaan, (Deegan dalam Oktavianti dan Wati, 2014). Teori Stakeholder ini lebih mempertimbangkan posisi para stakeholder yang menjadi pertimbangan utama bagi perusahaan dalam mengungkapkan atau tidak mengungkapkan suatu informasi di dalam laporan keuangan. Kelompok-kelompok stakeholder meliputi pemegang saham, pelanggan, pemasok, pemerintah dan masyarakat (Ulum dalam Puasanti, 2013).
Tujuan utama dari teori stakeholder adalah untuk membantu manajemen perusahaan dalam meningkatkan penciptaan nilai sebagai dampak dari aktifitas-aktifitas yang dilakukan dan meminimalkan kerugian yang mungkin muncul bagi stakeholder, Puasanti (2013). Pentingnya pengaruh stakeholder bagi reputasi perusahaan serta untuk mendapatkan keunggulan kompetitif, perusahaan tentu akan mencoba untuk mengelola hubungan dengan stakeholder melalui penyediaan informasi, biasanya dalam bentuk pengungkapan sukarela di dalam laporan tahunan atau website perusahaan, Suttipun (2012) dalam Prabowo (2014).

Dalam hal memuaskan stakeholder manajemen melakukan pengungkapan sukarela yang dibutuhkan para stakeholder berupa pengungkapan Intellectual Capital (Puasanti, 2013). Pengungkapan sukarela dalam bentuk pelaporan Intellectual Capital dapat dijadikan pertimbangan oleh perusahaan. Pengungkapan Intellectual Capital dapat dijadikan sarana bagi perusahaan untuk mengelola hubungan yang harmonis dengan stakeholder, Prabowo (2014).

Kesimpulan dari penjelasan diatas bahwa Teori stakeholder sangat erat hubungannya dengan pengungkapan Intellectual Capital, karena stakeholder berkepentingan untuk mempengaruhi manajemen dalam proses pemanfaatan seluruh potensi perusahaan, baik karyawan (human capital), aset fisik (capital employed), maupun structural capital, maka perubahan mampu menciptakan value added bagi perusahaan. Dengan meningkatkan Value added tersebut, maka kinerja keuangan perusahaan akan meningkat sehingga kinerja keuangan dimata stakeholder juga meningkat.

\section{Pengungkapan Intellectual Capital}

Pengungkapan Intellectual Capital berguna untuk memberikan informasi kepada stakeholder dengan sumber daya intelektual yang dimiliki oleh suatu perusahaan dan dapat meminimalkan asimetri (Julindra dan Susanto, 2015). Hendriksen (dalam Julindra dan Susanto, 2015) menyatakan informasi yang diberikan biasanya berupa pernyataan, catatan mengenai pernyataan, dan 
tambahan pengungkapan informasi yang terkait dengan catatan. Tiga konsep disclosure yang umumnya dikemukakan yaitu adequate (cukup), fair (wajar) dan full disclosure (pengungkapan yang lengkap). Intellectual Capital dikelompokkan menjadi dua yaitu: Pengungkapan Wajib (mandatory disclosure) dan pengungkapan sukarela (voluntary disclosure).

Pengungkapan wajib adalah informasi yang harus diungkapkan oleh emiten yang diatur oleh peraturan pasar modal suatu negara. sedangkan pengungkapan sukarela yaitu penyampaian informasi yang diberikan secara sukarela oleh perusahaan di luar pengungkapan wajib. Pengungkapan sukarela merupakan pengungkapan informasi yang melebihi persyaratan minimum dari peraturan pasar modal yang berlaku. Pengungkapan intellectual capital termasuk dalam pengungkapan sukarela, Nuswandari (2009) dalam Ramananda dan Nugrahanti (2014).

Pengungkapan intellectual capital dapat dikatakan sebagai laporan modal intelektual atau intellectual capital statement. Intellectual statement melaporkan aktivitas perusahaan melaporkan sumber dalam mengelola pengetahuan (knowledge management). Perusahaan melaporkan sumber daya yang dimiliki yang terkombinasi menjadi kemampuan, yang membuat perusahaan mampu melakukan sesuatu, Sihotang dan Winata (dalam Puasanti, 2013).

Salah satu pendekatan yang digunakan dalam penilaian dan pengukuran intangible asset tersebut adalah Intellectual Capital yang telah menjadi fokus perhatian dalam berbagai bidang, baik manajemen, teknologi informasi, sosiologi, maupun akuntansi, Petty dan Gutri (dalam Puasanti, 2013).

\section{Pengembangan Hipotesis}

\section{a. Ukuran Perusahaan terhadap Pengungkapan Intellectual Capital}

Ukuran perusahaan menggambarkan besar kecilnya sebuah perusahaan yang diukur dengan mengetahui total aktiva yang dimiliki perusahaan, Sujoko dan Soebiantoro (dalam Puasanti, 2013). semakin besar ukuran perusahaan maka semakin tinggi tingkat pengungkapannya tentang modal intelektual di dalam laporan tahunan.

\section{H1: Ukuran perusahaan berpengaruh positif terhadap Pengungkapan Intellectual Capital}

\section{b. Umur Perusahaan terhadap Pengungkapan Intellectual Capital \\ Lina (2013) Umur perusahaan}

menggambarkan periode waktu suatu perusahaan eksis dalam dunia bisnis. Semakin lama umur perusahaan semakin eksistensi dan mampu bersaing, perusahaan yang berumur lebih tua memiliki pengetahuan yang lebih mendalam tentang kebutuhan konstitusinya akan informasi mengenai perusahaan. Oleh karena itu, perusahaan yang lebih tua akan cenderung mengungkapkan informasi yang lebih lengkap, termasuk pengungkapan modal intelektual, karena pengungkapan informasi yang rinci dapat memberikan nilai tambah bagi perusahaannya, Puasanti (2013).

\section{H2: Umur perusahaan berpengaruh positif terhadap Pengungkapan Intellectual Capital}

\section{c. Leverage terhadap Pengungkapan Intellectual Capital}

Leverage merupakan pengukur besarnya aktiva yang dibiayai dengan utang. Utang yang digunakan untuk membiayai aktiva berasal dari kreditur, bukan dari pemegang saham ataupun investor. Menurut Looke (dalam Juliandra dan Susanto, 2015) perusahaan yang memliki leverage yang tinggi akan cenderung melakukan pengungkapan informasi yang lebih luas kepada pihak yang membutuhkan karena ingin dipandang bahwa perusahaan tersebut kredibel.

Dengan demikian, perusahaan dengan leverage yang tinggi akan cenderung mengungkapkan lebih banyak tentang intellectual capital di dalam annual report dibandingkan perusahaan dengan leverage yang rendah.

\section{H3: Leverage berpengaruh positif terhadap Pengungkapan Intellectual Capital}

\section{d. Return On Assets terhadap Pengungkapan Intellectual Capital}


Profitabilitas merupakan salah satu pengukuran bagi kinerja suatu perusahaan. Profitabilitas suatu perusahaan menunjukan kemampuan suatu perusahaan dalam menghasilkan laba selama periode tertentu pada tingkat penjualan, asset dan modal saham tertentu. Dalam penelitian ini, profitabilitas akan diukur dengan menggunakan Return On Assets, Ashari dan Putra (2016). Semakin tinggi profitabilitas perusahaan maka semakin tinggi pula tingkat pengungkapan intellectual capital.

\section{H4: Return On Assets berpengaruh positif terhadap Pengungkapan Intellectual Capital}

\section{e. Komisaris Independen terhadap Pengungkapan Intellectual Capital}

Komisaris independen sebagai pihak yang independen dan netral dalam perusahaan, diharapkan mampu menjembatani adanya asimetri informasi yang terjadi antara pihak pemilik dengan pihak manajer dengan mendorong anggota dewan komisaris lain untuk melakukan tugas pengawasan lebih baik lagi. Hal tersebut dilakukan agar dapat melindungi seluruh pemangku kepentingan dari tindakan agen yang menyimpang.

Jika pengawasan telah dilakukan dengan efektif, maka pengelolaan perusahaan akan dilakukan dengan baik pula, dan manajemen akan mengungkapkan semua informasi yang ada, termasuk informasi tentang intellectual capital, White et al., (2007) (dalam Oktavianti dan Wati, 2014).

\section{H5: Komisaris Independen berpengaruh positif terhadap Pengungkapan Intellectual Capital}

\section{METODE PENELITIAN}

\section{Populasi dan Sampel}

Populasi dalam penelitian ini adalah seluruh perusahaan manufaktur yang terdaftar di Bursa Efek Indonesia dalam periode 2013-2016. Jumlah populasi dalam penelitian ini adalah 144 perusahaan manufaktur. Pengambilan sampel yang dilakukan dengan metode purposive sampling. Purposive Sampling yaitu pemilihan anggota sampel dengan berdasarkan pada kriteria- kriteria tertentu. Perusahaan Manufaktur yang telah memenuhi kriteria sebagai sampel penelitian sebanyak 20 perbankan manufaktur selama 4 tahun penelitian, sehingga jumlah data yang digunakan pada penelitian ini sebanyak 80 data observasi.

\section{Definisi dan Pengukuran Variabel a. Variabel Independen}

Dalam penelitian ini terdapat 5 (lima) variabel independen (bebas), yaitu:

\section{1) Ukuran Perusahaan (X1)}

Ukuran perusahaan merupakan cerminan besar kecilnya perusahaan yang tampak dalam nilai total asset perusahaan yang terdapat pada neraca akhir tahun Sujoko dan Soebiantoro dalam Mahardika, dkk (2014). Dalam penelitian ini, ukuran perusahaan dihitung berdasarkan nilai natural $\log (\ln )$ dari total asset perusahaan pada akhir tahun. Rumus ukuran perusahaan :

$$
\text { Size }=\operatorname{Ln}(\text { Total Asset })
$$

Sumber : Dhanindra Prabowo (2014)

\section{2) Umur Perusahaan (X2)}

Variabel umur perusahaan juga dapat diartikan seberapa lama perusahaan tersebut ada. Alasan yang mendasari memasukan umur perusahaan ini adalah bahwa semakin tua umur perusahaan, maka memiliki pengalaman yang lebih banyak dalam pengelolaan dan pemeliharaan intellectual capital akan menjadi lebih optimal dan dengan sendirinya dapat meningkatkan kinerja intellectual capital tersebut.

Dalam penelitian ini umur perusahaan dihitung dari lamanya perusahaan tersebut go public. Pengukuran firm age dilakukan menggunakan rumus sebagai berikut:

Firm age $=$ Tahun laporan keuangan terakhir (penelitian) -Tahun berdirinya perusahaan

Sumber: Fitria Ingga Saemargani, 2015

\section{3) Leverage (X3)}

Leverage merupakan perbandingan besarnya dana yang disediakan pemiliknya dengan dana yang dipinjam dari kreditur, Puasanti (2013). Rasio ini menunjukkan kemampuan modal sendiri untuk memenuhi seluruh kewajiban perusahaan. Rumus untuk menghitung Leverage, yaitu: 


$$
\text { DER }=\frac{\text { Total Hutang }}{\text { Total Equity }}
$$

Sumber : Novianus (2016)

\section{4) Return On Asset $\left(\mathrm{X}_{4}\right)$}

Profitabiltas yang diukur menggunakan Return On Asset adalah kemampuan perusahaan dalam menghasilkan laba dalam kegiatan operasi merupakan fokus utama dalam penilaian prestasi perusahaan, Oktavianti dan Wati (2014). Rumus untuk menghitung ROA yaitu :

$$
\text { ROA }=\frac{\text { Laba Bersih Setelah Pajak }}{\text { Total Aktiva }}
$$

Sumber : Achmad Fauzi (2016)

\section{5) Komisaris Independen $\left(X_{5}\right)$}

Komisaris independen adalah anggota dewan komisaris yang tidak memiliki hubungan keuangan, kepengurusan, kepemilikan saham dan/atau hubungan keluarga dengan anggota dewan komisaris lainnya, direksi dan/atau pemegang saham pengendali atau hubungan lain yang dapat mempengaruhi kemampuannya untuk bertindak independen, Sari (dalam Dwipayani dan Putri, 2016). Rumus untuk menghitung Komisaris Independen yaitu :

$$
\mathrm{KI}=\frac{\text { Jumlah Komisaris Independen }}{\text { Jumlah Dewan Komisaris }}
$$

Sumber: Dwipayani dkk, E-Jurnal Ekonomi dan Bisnis (2016)

\section{b. Variabel Dependen}

Variabel dependen yang digunakan dalam penelitian ini adalah sebagai berikut:

Intellectual Capital yang diukur yaitu dengan Value Added Intellectual Capital $\left(\mathrm{VAIC}^{\mathrm{TM}}\right.$ ) yang merupakan basis pengukuran pokok variabel dalam penelitian ini. Kinerja Intellectual Capital yang diukur dengan Value Added yang diciptakan oleh physical capital, human capital dan structural capital.Tahap pertama dengan menghitung Value Added (VA). VA dihitung dengan menggunakan cara yaitu sebagai berikut :

$$
\text { VA }(\text { Value Added })=\text { OUT }- \text { IN }
$$

Sumber: Achmad Fauzi (2016)

Value Added $(\mathrm{VA})=$ Hasil dari Selisih antara output dan input

Output (OUT) = Total Penjualan dan pendapatan

Input $(\mathrm{IN}) \quad=$ Beban penjualan dan biayabiaya lain (selain beban karyawan)

$\mathrm{VAIC}^{\mathrm{TM}}$ merupakan gabungan dari ketiga indikator value added yang dapat dinyatakan sebagai berikut:

\section{1) Physical Capital (VACA-Value Added Capital Employed)}

VACA merupakan perbandingan antara value added (VA) dengan ekuitas perusahaan (CE), rasio ini menunjukkan kontribusi yang dibuat oleh setiap unit dari $\mathrm{CE}$ terhadap value added organisasi. Formulasi dan tahapan perhitungan nilai VACA adalah sebagai berikut:

$$
\text { VACA }=\frac{V A(\text { Value Added })}{C E(\text { Capital Employed })}
$$

Sumber: Ihyaul Ulum (2009)

Keterangan:

$V A=$ Value Added

$C E=$ Capital Employed: dana yang tersedia (Ekuitas, laba bersih)

\section{2) Human Capital (VAHU-Value Added Human Capital) \\ VAHU menunjukkan kontribusi yang dibuat} oleh setiap rupiah yang diinvestasikan dalam HC terhadap value added organisasi. Formulasi dan tahapan perhitungan nilai VAHU adalah sebagai berikut:

$V A H U=\frac{V A(\text { Value Added })}{H C(\text { Human Capital })}$

Sumber: Ihyaul Ulum (2009)

Keterangan :

$V A=$ Value Added

$H U=$ Human Capital (Beban Gaji Karyawan)

VAHU merupakan indikator kualitas sumber daya manusia yang dimiliki perusahaan. 


\section{3) Structural Capital (STVA-Structural Capital Value Added)}

STVA mengukur jumlah modal struktural (SC) yang dibutuhkan untuk menghasilkan 1 rupiah dari Value Added (VA) dan merupakan indikasi bagaimana keberhasilan modal struktural (SC) dalam penciptaan nilai SC. Formulasi dan tahapan perhitungan nilai STVA adalah sebagai berikut:

$$
\text { STVA }=\frac{\text { SC }(\text { Structural Capital })}{\text { Value Added }(\text { VA })}
$$

Sumber: Ihyaul Ulum (2009)

Keterangan:

$S C=$ Structural capital $=\mathrm{VA}-\mathrm{HC}$

$V A=$ Value Added

$\mathrm{VAIC}^{\mathrm{TM}}=\mathrm{VACA}+\mathrm{VAHU}+\mathrm{STVA}$

Value Added Intellectual Coefficient $\left(\mathrm{VAIC}^{\mathrm{TM}}\right.$ ) mengindikasikan kemampuan organisasi. VAIC ${ }^{\mathrm{TM}}$ dapat juga dianggap sebagai BPI (Business Performance Indicator).

\section{Teknik Analisis Data}

Dalam penelitian ini, teknik analisis data yang digunakan adalah analisis regresi data panel dengan bantuan sofware pengolah data statistik yaitu Eviews 9.0. Model regresi data panel dapat ditulis sebagai berikut (Eksandy dan Heriyanto, 2017):

$\mathrm{Yit}=\alpha+\beta 1 \mathrm{X} 1 i t+\beta 2 \mathrm{X} 2 i t+\beta 3 \mathrm{X} 3 i t+\beta 4 \mathrm{X} 4 i t+\beta 5 \mathrm{X} 5 i t+\varepsilon i t$

Keterangan:

$\mathrm{Y}=$ Pengungkapan Intellectual Capital

$\alpha \quad=$ Konstanta

$\beta=$ Koefisien Regresi Variabel Independen

$\mathrm{X} 1=$ Ukuran Perusahaan

$\mathrm{X} 2$ = Umur Perusahaan

$\mathrm{X} 3$ = Leverage

$\mathrm{X} 4=$ Return On Assets

$\mathrm{X} 5=$ Komisaris Independen

$\mathrm{i} \quad=$ Perusahaan yang diteliti

$\mathrm{t}=$ waktu

$\varepsilon \quad=$ Error Term
HASIL DAN PEMBAHASAN

1. Analisis Statistik Deskriptif

\begin{tabular}{|l|c|c|c|c|c|c|}
\hline & VAIC & SIZE & FIRMAGE & DER & ROA & KI \\
\hline Mean & 6.100513 & 22.70700 & 37.05000 & 0.643645 & 0.093696 & 0.413875 \\
\hline Median & 5.509000 & 24.31000 & 40.00000 & 0.571100 & 0.093150 & 0.400000 \\
\hline Maximum & 18.67100 & 30.35000 & 59.00000 & 1.973600 & 0.209400 & 0.670000 \\
\hline Minimum & 1.974000 & 12.27000 & 5.000000 & 0.077000 & 0.000400 & 0.250000 \\
\hline Std. Dev. & 3.121842 & 5.889501 & 12.19660 & 0.422476 & 0.051640 & 0.102827 \\
\hline Skewness & 1.459501 & -0.184304 & -0.555845 & 1.129240 & 0.151990 & 1.093602 \\
\hline Kurtosis & 5.876517 & 1.412763 & 3.190204 & 4.019479 & 2.384997 & 3.384776 \\
\hline & & & & & & \\
\hline Jarque-Bera & 55.98306 & 8.850645 & 4.240101 & 20.46688 & 1.568777 & 16.43972 \\
\hline Probability & 0.000000 & 0.011970 & 0.120026 & 0.000036 & 0.456399 & 0.000269 \\
\hline & & & & & & \\
\hline Sum & 488.0410 & 1816.560 & 2964.000 & 51.49160 & 7.495700 & 33.11000 \\
\hline Sum Sq. Dev. & 769.9259 & 2740.211 & 11751.80 & 14.10042 & 0.210668 & 0.835299 \\
\hline & & & & & & \\
\hline Observations & 80 & 80 & 80 & 80 & 80 & 80 \\
\hline Sumber & & & & & & \\
\hline
\end{tabular}

\section{Sumber: Output Eviews 9.0}

dapat dıjelaskan sebagaı berıkut:

a. Mean adalah nilai rata-rata suatu kelompok data atau teknik penjelasan kelompok yang didasarkan atas nilai rata-rata dari kelompok tersebut. Mean terbesar dihasilkan oleh umur perusahaan (FIRM AGE) sebesar 37,05000 yang berada di PT. Mayora Indah Tbk dan PT. Surya Toto Indonesia Tbk pada tahun 2014, sementara mean terkecil diperoleh oleh variabel Return On Assets (ROA) sebesar 0,093696 yang berada di PT. Astra International Tbk pada tahun 2014. Sementara itu mean dari variabel lainnya yaitu Intellectual Capital (VAIC) sebesar 6,100513, Ukuran perusahaan (SIZE) sebesar 22,70700, Leverage (DER) sebesar 0,643645 dan komisaris independen (KI) sebesar 0.413875 .

b. Median adalah nilai tengah atau nilai yang letaknya ditengah dari data yang telah diurutkan dari nilai terkecil sampai terbesar. Median terbesar dihasilkan oleh umur perusahaan (FIRM AGE) sebesar 40,00000 yang berada di PT. Semen Baturaja (Persero) Tbk pada tahun 2014 dan PT. Champion Pacific Indonesia Tbk pada tahun 2015, sementara median terkecil diperoleh oleh variabel Return On Assets 
(ROA) sebesar 0,093150 yang berada di PT. Gudang Garam Tbk pada tahun 2014. Sementara itu median dari variabel lainnya yaitu Intellectual Capital (VAIC) sebesar 5,509000, ukuran perusahaan (SIZE) sebesar 24,31000, Leverage (DER) sebesar 0,571100 dan komisaris indepeden (KI) sebesar 0.400000 .

c. Maximum adalah nilai terbesar dalam sebuah kelompok data. Maximum terbesar dihasilkan oleh umur perusahaan (FIRM AGE) sebesar 59,00000 yang berada di PT. Astra International Tbk pada tahun 2016, sementara maximum terkecil diperoleh oleh Return On Assets (ROA) sebesar 0,209400 yang berada di PT. Arwana Citramulia Tbk pada tahun 2013. Sementara itu maximum variabel lainnya yaitu yaitu Intellectual Capital (VAIC) sebesar 18,67100, Ukuran perusahaan (SIZE) sebesar 30,35000, Leverage (DER) sebesar 1,973600 dan komisaris independen (KI) sebesar 0,670000.

d. Minimum adalah nilai terkecil dalam sebuah kelompok data. Minimum terbesar dihasilkan oleh ukuran perusahaan (SIZE) sebesar

Redundant Fixed Effects Tests

Equation: EQ01

Test cross-section fixed effects

\begin{tabular}{|llll|}
\hline \hline Effects Test & Statistic & d.f. & Prob. \\
\hline \hline \multirow{2}{*}{ Cross-section F } & 9.535228 & $(19,55)$ & 0 \\
& 116.57727 & & 0.000 \\
Cross-section Chi-square 1 & 19 & 0 \\
\hline \hline
\end{tabular}

12,27000 yang berada di PT. Astra International Tbk pada tahun 2013, sementara minimum terkecil diperoleh oleh variabel Return On Assets (ROA) sebesar 0,000400 yang berada di PT. Star Petrochem Tbk pada tahun 2014 dan tahun 2015. Sementara itu minimum variabel lainnya yaitu Intellectual Capital (VAIC) sebesar 1,974000, umur perusahaan (FIRM AGE) sebesar 5,000000, Leverage (DER) sebesar 0,077000 dan komisaris independen (KI) sebesar 0,250000. e. Standar deviasi adalah ukuran dispersi atau penyebaran data. Nilai standar deviasi terbesar dialami oleh variabel umur perusahaan (FIRM AGE) yaitu sebesar 12,19660 yang berarti bahwa variabel umur perusahaan (FIRM AGE) memiliki tingkat risiko yang lebih tinggi dibandingkan dengan variabel-variabel yang lain. Sementara variabel Return On Assets (ROA) mempunyai tingkat resiko yangpaling rendah, yaitu sebesar 0,051640. Hal ini menunjukkan bahwa Return On Assets (ROA) selama periode penelitian mengalami perubahan yang tidak terlalu fluktuatif.

\section{Pemilihan Model Regresi Data Panel}

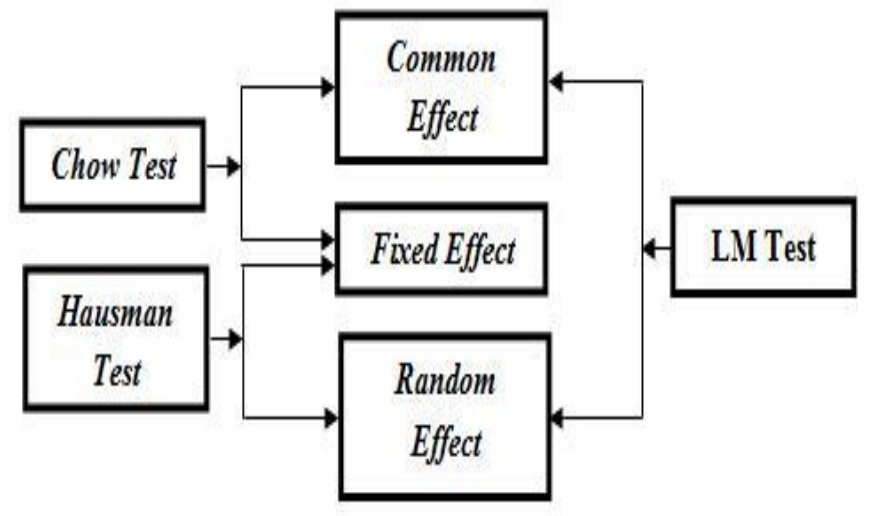

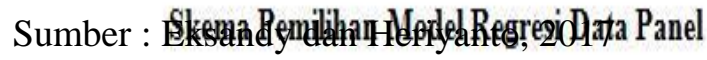

\section{a. Chow Test}

Hipotesis dalam Chow Test adalah sebagai berikut:

H0: Model mengikuti Common Effect Model (CEM) jika Probabilitas Cross-section F dan Cross-section chi-square $>\alpha(0,05)$

Ha: Model mengikuti Fixed Effect Model (FEM) jika Probabilitas Cross-section F dan Crosssection chi-square $<\alpha(0,05)$

\section{Hasil Chow Test}

Sumber: Output Eviews 9.0

Berdasarkan hasil pengujian di atas dapat dilihat bahwa nilai Probablitas (Prob.) Crosssection F sebesar 0.0000 dan Cross-section Chisquare sebesar 0.0000 , dimana angka tersebut lebih kecil dari $\alpha(0,05)$ maka dapat disimpulkan bahwa Fixed Effect Model (FEM) lebih baik digunakan daripada Common Effect Model (CEM). 


\section{b. Hausman Test}

Hipotesis dalam Hausman test adalah sebagai berikut:

H0: Model mengikuti Random Effect Model (REM) jika nilai Probabilitas (Prob.) Crosssection random $>\alpha(0,05)$

Ha: Model mengikuti Fixed Effect Model (FEM) jika nilai Probabilitas (Prob.) Cross-section random $<\alpha(0,05)$

Hasil Haussman Test

Correlated Random Effects - Hausman

Test

Equation: EQ01

Test cross-section random effects

\begin{tabular}{|llll|}
\hline \hline $\begin{array}{l}\text { Test } \\
\text { Summary }\end{array}$ & $\begin{array}{l}\text { Chi-Sq. } \\
\text { Statistic }\end{array}$ & $\begin{array}{l}\text { Chi-Sq. } \\
\text { d.f. }\end{array}$ & Prob. \\
\hline \hline $\begin{array}{l}\text { Cross-section } \\
\text { random }\end{array}$ & 1.146145 & 5 & 0.9499 \\
\hline
\end{tabular}

Sumber: Output Eviews 9.0

Berdasarkan hasil pengujian diatas dapat

\begin{tabular}{|l|l|l|l|}
\hline No & Metode & Pengujian & Hasil \\
\hline 1 & Chow test & CEM vs FEM & FEM \\
\hline 2 & Hausman test & REM vs FEM & REM \\
\hline 3 & $\begin{array}{l}\text { Langrange } \\
\text { Multiplier test }\end{array}$ & CEM vs REM & REM \\
\hline \multicolumn{3}{|c|}{ dilihat bahwa nilai Probabilitas (Prob.) Cross- }
\end{tabular}

section random sebesar 0.9499 , dimana angka tersebut lebih besar dari $\alpha(0,05)$, maka dapat disimpulkan bahwa Random Effect Model (REM) lebih layak digunakan dibandingkan Fixed Effect Model (FEM).

\begin{tabular}{|llll|}
\hline & \multicolumn{4}{l}{0.5355} & Mean dependent \\
R-squared & 06 & ar & 1.708858 \\
Adjusted R- & 0.5041 & S.D. dependent \\
squared & 21 & var & 1.927194 \\
S.E. of & 1.3571 & Sum squared \\
regression & 04 & resid & 136.2882 \\
& 17.062 & Durbin-Watson \\
F-statistic & 64 & stat & 1.472508 \\
Prob(F- & 0.0000 & & \\
statistic) & 00 & & \\
\hline
\end{tabular}

c. Lagrange Multiplier Test

\begin{tabular}{|c|c|c|c|}
\hline \multicolumn{4}{|c|}{$\begin{array}{l}\text { Lagrange Multiplier Tests for Random Effects } \\
\text { Null hypotheses: No effects } \\
\text { Alternative hypotheses: Two-sided (Breusch- } \\
\text { Pagan) } \\
\text { and one-sided } \\
\quad \text { (all others) alternatives }\end{array}$} \\
\hline & \multicolumn{3}{|c|}{ Test Hypothesis } \\
\hline & Cross-section & Time & Both \\
\hline $\begin{array}{l}\text { Breusch- } \\
\text { Pagan }\end{array}$ & $\begin{array}{l}55.09204 \\
(0.0000)\end{array}$ & $\begin{array}{l}1.707973 \\
(0.1912) \\
\end{array}$ & $\begin{array}{l}56.8000 \\
1 \\
(0.0000)\end{array}$ \\
\hline
\end{tabular}

Hipotesis dalam Lagrange Multiplier Test adalah sebagai berikut:

H0: Model mengikuti Common Effect Model (CEM) jika nilai Probabilitas (Prob.) Cross-section Breush-pagan $>\alpha(0,05)$

Ha: Model mengikuti Random Effect Model (REM) jika nilai Probabilitas (Prob.) Crosssection Breush-pagan $<\alpha(0,05)$

Hasil Lagrange Multiplier Test

Sumber: Output Eviews 9.0

Berdasarkan hasil pengujian di atas dapat dilihat bahwa nilai Probabilitas Cross-Section Breausch-pagan sebesar 0.0000 , dimana angka tersebut lebih kecil dari $\alpha(0,05)$, maka dapat disimpulkan bahwa Random Effect Model (REM) lebih layak digunakan dibandingkan Fixed Effect Model (FEM).

\section{d. Kesimpulan Model \\ Sumber: Output Eviews 9.0}

Berdasarkan hasil ke tiga pengujian yang sudah dilakukan maka dapat disimpulkan bahwa Model Regresi Data Panel yang lebih baik digunakan Random Effect Model (REM) lebih baikdalam mengestimasi pengaruh Ukuran perusahaan, Umur perusahaan, Leverage, Return On Assets dan Komisaris Independen terhadap pengungkapan Intellectual Capital pada perusahaan manufaktur periode 2013-2016.

\section{Uji Hipotesis \\ a. Uji F}


Berdasarkan pada tabel di atas menunjukkan bahwa nilai F-statistic sebesar 17,06264 sementara nilai $\mathrm{F}$ Tabel dengan tingkat $\alpha 5 \%$, df1 $(\mathrm{k}-1)=5$ dan df $2(\mathrm{n}-\mathrm{k})=74$ didapat nilai $\mathrm{F}$ Tabel sebesar 2,33828. Dengan demikian Fstatistic $(17,06264)>$ F Tabel $(2,33828)$ dan nilai Prob (F-statistic) sebesar $0.000000<\alpha$ $(0,05)$ sehingga dapat disimpulkan bahwa $\mathrm{Ha}$ diterima, maka dengan demikian dapat disimpulkan bahwa variabel-variabel independen dalam penelitian ini yang terdiri dari SIZE, FIRM AGE, DER, ROA dan KI secara bersama-sama berpengaruh terhadap pengungkapan Intellectual Capital (VAIC).

\section{b. R-squared (Koefisien Determinasi)}

Sumber: Output Eviews 9.0

Berdasarkan pada tabel di atas, dapat dilihat bahwa nilai R-squared sebesar 0.535506 yang berarti bahwa variasi perubahan naik turunnya pengungkapan Intellectual Capital (VAIC) dapat dijelaskan oleh Ukuran perusahaan, Umur perusahaan, Leverage, Return On Assets dan Komisaris Independensebesar 53,55\%, sementara sisanya yaitu sebesar $46,45 \%$ dijelaskan oleh variabel-variabel lain yang tidak diteliti dalam penelitian ini.

\section{c. Uji t}

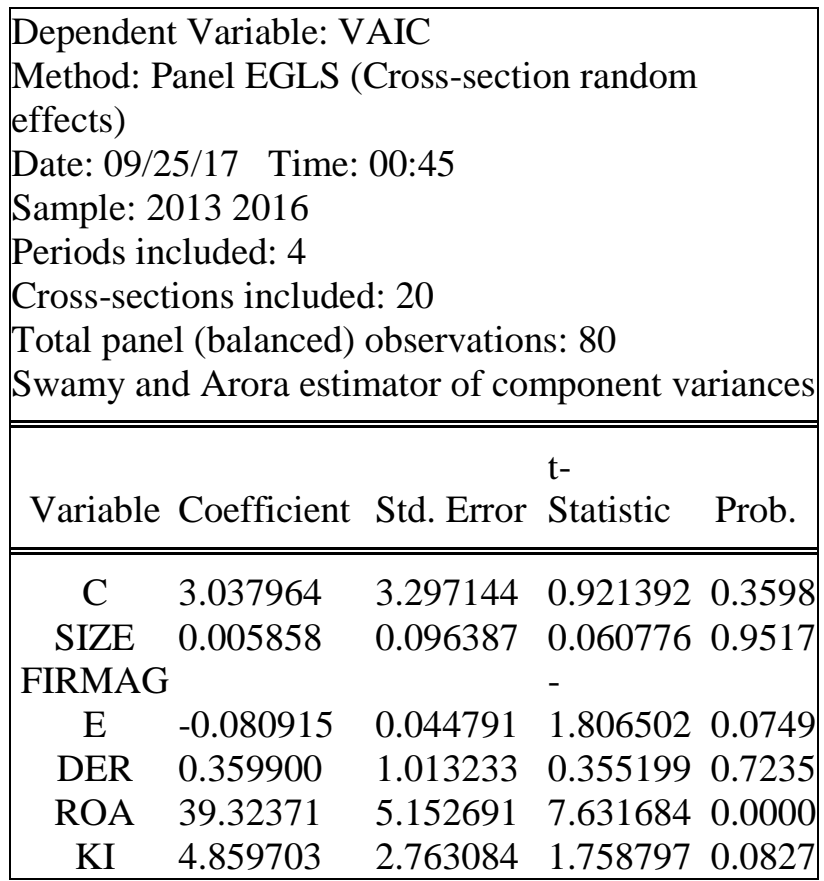

Sumber: Output Eviews 9.0
Berdasarkan pada tabel di atas menunjukkan bahwa :

1) Nilai t-statistic SIZE sebesar 0,060776 sementara t Tabel dengan tingkat $\alpha=5 \%$, df $(\mathrm{n}-\mathrm{k})=75$ didapat nilai $\mathrm{t}$ Tabel sebesar 1,99210. Dengan demikian bahwa t-statistic $(0,060776)$ < $(1,99210)$ dan nilai Prob. 0,9517> 0,05 maka dapat disimpulkan bahwa variabel SIZE dalam penelitian ini tidak memiliki pengaruh terhadap pengungkapan Intellectual Capital. Maka dapat disimpulkan bahwa $\mathbf{H}_{\mathbf{1}}$ dalam penelitian ini ditolak.

2) Nilai t-statistic FIRM AGE sebesar 1.806502sementara $\mathrm{t}$ Tabel dengan tingkat $\alpha$ $=5 \%$, df $(\mathrm{n}-\mathrm{k})=75$ didapat nilai $\mathrm{t}$ Tabel sebesar

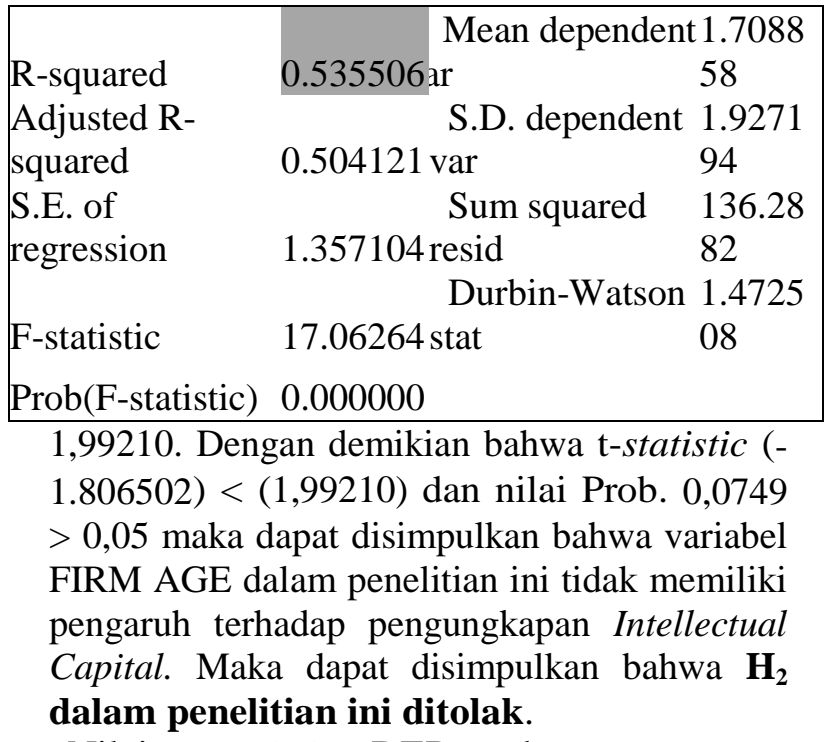

3) Nilai t-statistic DER sebesar 0.355199 sementara t Tabel dengan tingkat $\alpha=5 \%$, df $(\mathrm{n}-\mathrm{k})=75$ didapat nilai $\mathrm{t}$ Tabel sebesar 1,99210. Dengan demikian bahwa t-statistic (0.355199) < $(1,99210)$ dan nilai Prob. $0.7235>0,05$ maka dapat disimpulkan bahwa variabel DER dalam penelitian ini tidak memiliki pengaruh terhadap pengungkapan Intellectual Capital. Maka dapat disimpulkan bahwa $\mathbf{H}_{\mathbf{3}}$ dalam penelitian ini ditolak.

4) Nilai t-statistic ROA sebesar 7.631684 sementara t Tabel dengan tingkat $\alpha=5 \%$, df $(\mathrm{n}-\mathrm{k})=75$ didapat nilai $\mathrm{t}$ Tabel sebesar 1,99210. Dengan demikian bahwa t-statistic (7.631684) $>(1,99210)$ dan nilai Prob. $0,0000<0,05$ maka dapat disimpulkan bahwa variabel ROA dalam penelitian ini memiliki pengaruh terhadap pengungkapan Intellectual Capital. Maka dapat disimpulkan bahwa $\mathbf{H}_{4}$ dalam penelitian ini diterima. 
5) Nilai t-statistic KI sebesar 1.758797, sementara t Tabel dengan tingkat $\alpha=5 \%$, df $(\mathrm{n}-\mathrm{k})=75$ didapat nilai $\mathrm{t}$ Tabel sebesar 1,99210. Dengan demikian bahwa t-statistic $(1.758797)<(1,99210)$ dan nilai Prob. $0.0827>0,05$ maka dapat disimpulkan bahwa variabel KI dalam penelitian ini tidak memiliki pengaruh terhadap pengungkapan Intellectual Capital. Maka dapat disimpulkan bahwa $\mathbf{H}_{5}$ dalam penelitian ini ditolak.

\section{Simpulan}

Berdasarkan hasil analisis data dan pembahasan yang telah diuraikan, maka kesimpulan dari penelitian ini adalah sebagai berikut: (1) Ukuran perusahaan, Umur perusahaan, Leverage, Return On Assets dan Komisaris Independen secara bersama-sama berpengaruh terhadap Pengungkapan Intellectual Capital. Hal ini ditunjukkan oleh nilai $\mathrm{F}$ hitung sebesar 17,06264, sementara nilai $F$ Tabel 2,33828. Dengan demikian $F$ hitung $(17,06264)>\mathrm{F}$ Tabel $(2,33828)$ dengan nilai Prob $0,000000<\alpha(0,05)$. (2) (2) Variabel ukuran perusahaan (X1) secara parsial tidak berpengaruh terhadap Pengungkapan Intellectual Capital (Y). Hal ini dibuktikan dengan nilai t hitung $(0,060776)<\mathrm{t}$ Tabel $(1,99210)$ dan nilai siginifikan sebesar 0,9517 > taraf signifikan 0,05. (3) Variabel umur perusahaan (X2) secara parsial tidak pengaruh terhadap Pengungkapan Intellectual Capital (Y). Hal ini dibuktikan dengan nilai t hitung (1.806502) < t Tabel $(1,99210)$ dan nilai signifikan sebesar 0,0749 > taraf signifikan 0,05. (4) Variabel leverage (X3) secara parsial tidak berpengaruh terhadap Pengungkapan Intellectual Capital (Y). Hal ini dibuktikan dengan nilai $\mathrm{t}$ hitung $(0.355199)<\mathrm{t}$ Tabel $(1,99210)$ dan nilai signifikan. sebesar $0.7235>$ taraf signifikan 0,05. (5) Variabel Return On Assets (X4) secara parsial berpengaruh positif dan signifikan terhadap Pengungkapan Intellectual Capital (Y). Hal ini dibuktikan dengan nilai t hitung (7.631684) $>\mathrm{t}$ Tabel $(1,99210)$ dan nilai signifikan sebesar $0,0000<$ taraf signifikan 0,05. (6) Variabel Komisaris Independen (X5) secara parsial tidak berpengaruh terhadap Pengungkapan Intellectual Capital (Y). Hal ini dibuktikan dengan nilai t hitung (1.758797) $<\mathrm{t}$ Tabel $(1,99210)$ dan nilai signifikan sebesar $0.0827>$ taraf signifikan 0,05 .
Penelitian ini memiliki beberapa keterbatasan, antara lain: 1) Periode penelitian relatif masih singkat hanya 4 tahun, yaitu selama periode 2013-2016. (2) Sampel Perusahaan yang diambil menggunakan purposive sampling Perusahaan Manufaktur sehingga mengurangi jumlah sampel.

Saran yang hendak peneliti sampaikan untuk penelitian selanjutnya adalah sebagai berikut: (1) Menambahkan periode yang lebih panjang agar hasil penelitian selanjutnya bisa lebih mengeneralisasi dan lebih baik dalam segala aspek. (2) Agar penelitian selanjutnya menambahkan jumlah sampel agar dapat menunjang dan memberikan hasil penelitian yang lebih baik. (3) Agar hasil penelitian dimasa yang akan datang lebih baik, disarankan untuk menambah variabel seperti karakteristik perusahaan..

\section{Referensi}

Agoes, Sukrisno. 2012. Petunjuk Praktis Pemeriksaan oleh Akuntan Publik. Edisi 4: Salemba Empat.

Ashari dan Putra. 2016. Pengaruh Umur Perusahaan, Ukuran Perusahaan, Profitabilitas, Leverage, dan Komisaris Independen terhadap Pengungkapan Modal Intelektual. E-Jurnal Akuntansi Universitas Udayana.14.3, ISSN: 23028559, Hal: 1699-1726.

Basuki, Agus Tri dan Prawoto, Nano. 2016. Analisis Regresi Data Panel dalam Penelitian Ekonomi \& Bisnis: Dilengkapi Aplikasi SPSS \& EVIEWS. Depok: PT Rajagrafindo Persada.

Dwipayani dan Putri. 2016. Faktor-faktor yang berpengaruh pada Pengungkapan Intellectual capital. E-Jurnal Ekonomi dan Bisnis Universitas Udayana 5.11 (2016): 3793-3822.

Eksandy, Arry dan Freddy Heriyanto. (2017). Metode Penelitian Akuntansi dan Keuangan (Dilengkapi Analisis Regresi Data Panel dan Regresi Logistik Data Panel Menggunakan Program Eviews). Tangerang: Fakultas Ekonomi dan Bisnis Universitas Muhammadiyah Tangerang.

Eksandy dan Hakim. 2016. Pengaruh Ukuran Perusahaan, Profitabilitas, dan Leverage Terhadap Pengungkapan Islamic Social Reporting (ISR) pada Perusahaan Syariah Di Indonesia Tahun 2011-2015. Riset Akuntansi dan Keuangan Indonesia 
Ghozali, 2013. Analisis Multi variat dan Ekonometrika: Teori, Konsep, dan Aplikasi dengan Eviews. Badan Penerbit Universitas Diponegoro, Semarang

Harjito Agus dan Martono, (2012). Manajemen Keuangan. Edisi 2. Yogyakarta: Ekonisia

Ikatan Akuntansi Indonesia. 2000. PSAK No. 19: Aktiva Tidak Berwujud (Revisi 2000)

Ikatan Akuntan Indonesia. 2009. Pernyataan Standar Akuntansi Keuangan No.19.

Ikatan Akuntan Indonesia. 2013. Pernyataan Standar Keuangan 01: Penyajian Laporan Keuangan (Revisi 2013)

Julindra dan Susanto 2015. Analisis Pengaruh Ukuran Perusahaan, Leverage, Profitabilitas dan Umur Listing Terhadap Pengungkapan Modal Intelektual pada Perusahaan Manufaktur yang terdaftar di Bursa Efek Indonesia (BEI) pada tahun 2012-2014. Jurnal Ekonomi/Volume XX, No. 01, Maret 2015: 103-119.

Kasmir, 2016.“Analisis Laporan Keuangan”. PT Raja Grafindo Persada, Jakarta.

Lina, 2013. Faktor-faktor Penentu Pengungkapan Modal Intelektual. Media Riset Akuntansi Vol.3 No.1 Februari 2013. ISSN 20882106.

Mahardika, Khafid dan Liana. 2014. Pengaruh Struktur Kepemilikan, Umur Perusahaan terhadap Kinerja Intellectual Capital. Accounting Analysis Journal. ISSN 22526765.

Novianus. 2016. Hubungan Antara Ukuran Perusahaan, Leverage, Profitabilitas, dengan Manajemen Laba. Skiripsi Fakultas Ekonomi dan Bisnis. Universitas Sanata Dharma Yogyakarta.

Nugroho Ahmadi, 2012. Faktor-faktor yang mempengaruhi Intellectual Capital Disclosure (ICD). Accounting Analysis Journal ISSN 2252-6765.

Oktavianti dan Wati. 2014. Faktor-faktor yang mempengaruhi Pengungkapan Intellectual Capital. Jurnal Ilmu \& Riset Akuntansi Vol. 3 No. 5 (2014). Sekolah Tinggi Ilmu Ekonomi Indonesia (STIESIA) Surabaya.

Prabowo, Dhanindra. 2014. Analisis Faktorfaktor yang mempengaruhi Intellectual Capital Disclosure dan Pengaruh Intellectual Capital Disclosure terhadap Market Capitalization.
Ramadhania, Tara dan Jelita. Pengaruh Intellectual Capital terhadap Profitabilitas pada Perusahaan Manufaktur yang terdaftar di Bursa Efek Indonesia. Jurnal Riset Akuntansi dan Perpajakan JRAP Vol. 2, No. 1, Juni 2015, hal 1-18. ISSN 2339 1545

Ramananda dan Nugrahanti. 2014. Analisis Pengungkapan Intellectual Capital berdasarkan Profitabilitas, Leverage, dan Size Perusahaan (Perbandingan antara Perusahaan Perbankan Di Indonesia dan Di Thailand). Dinamika Akuntansi, Keuangan dan Perbankan, Mei 2014, Hal: 84-98 Vol. 3, No. 1. ISSN: 1979-4878.

Sugiyono, 2012. Metode Penelitian Kualitatif. Penerbit CV. Alfabeta: Bandung

----------, 2014. Metode Penelitian Kuantitatif Kualitatif dan $R \& D$. Bandung: Alfabeta.

----------, 2016. Metode Penelitian Kuantitatif Kualitatif dan $R \& D$. Bandung: Alfabeta.

Ulum, Ihyal. 2009, Intellectual Capital: Konsep Dan Kajian Empiris, Yogyakarta: Graha Ilmu

Winarno, Wahyu, Winx. 2015. Analisis Ekonometrika dan Statistika dengan Eviews Edisi 4.UPP. STIM YKPN. Yogyakarta 
